\section{It is Time to Reconsider Position of Metabolic Syndrome in Preventive Medicine}

Key words: metabolic syndrome, cardiovascular disease, obesity, mortality, preventive medicine

\section{(Intern Med 52: 1851, 2013)}

(DOI: 10.2169/internalmedicine.52.0741)

To the Editor The incidence of metabolic syndrome (MS) is believed to be a useful tool for identifying future cases of diabetes in Japanese individuals. However, both MS and Japanese MS (JMS) were found to be poor predictors of diabetes in a Japanese health screening population (1). The predictive value of JMS was based on the presumption that visceral adipose tissue (VAT) exerts adverse effects on the mortality of patients with obesity and cardiovascular disease (CVD), whereas subcutaneous abdominal adipose tissue exerts favorable effects in such patients. However, this assumption is disproved by the fact that VAT is not significantly associated with all-cause, obesity-related, or CVDrelated mortality after adjusting for the body mass index, a marker of general obesity, as demonstrated in a long-term follow-up study of Japanese Americans (2). It has been suggested that increased VAT does not directly cause metabolic dysfunction, as omentectomy does not have a significant ancillary impact on the components of MS and does not induce important changes in inflammatory mediators in patients undergoing Roux-en-Y gastric bypass surgery (3). Although obesity is not prevalent in Japan, JMS is considered to be the most important target in preventive medicine by several Japanese medical societies and the Japanese government, without evidence. However, among the factors of obesity, high blood pressure, hyperglycemia assessed according to the hemoglobin A1c (HbA1c) level, a high triglyceride level, and a low HDL cholesterol level, which represent the five components of MS, only high blood pressure and hyperglycemia were found to be significantly associated with CVD mortality following adjustment for the total cholesterol level and smoking over a 15-years follow-up in the NIPPON DATA90. In that study, no significant increases in CVD mortality were observed with respect to moderate metabolic risk factor clustering (3), and the population attributable fraction of CVD deaths was $40.9 \%$ in men and $11.9 \%$ in women among smokers without MS and $7.1 \%$ in men and $3.9 \%$ in women among smokers with MS (4). These results suggest that clinicians should focus more on hyperglycemia, high blood pressure and smoking than on MS in order to prevent CVD in Japan.

The author states that he has no Conflict of Interest (COI).

Eiji Oda

\section{References}

1. Oda E, Aizawa Y. Metabolic syndrome is a poor predictor of diabetes in a Japanese health screening population. Intern Med 52: 721-725, 2013.

2. McNeely MJ, Shofer JB, Leonetti DL, Fujimoto WY, Boyko EJ. Associations among visceral fat, all-cause mortality, and obesityrelated mortality in Japanese Americans. Diabetes Care 35: 296298, 2012.

3. Herrera MF, Pantoja JP, Velázquez-Fernández D, et al. Potential additional effect of omentectomy on metabolic syndrome, acutephase reactants, and inflammatory mediators in grade III obese patients undergoing laparoscopic Roux-en-Y gastric bypass: a randomized trial. Diabetes Care 33: 1413-1418, 2010.

4. Kadota A, Miura K, Okamura T, et al. Relationship of moderate metabolic risk factor clustering to cardiovascular disease mortality in non-lean Japanese: a 15-year follow-up of NIPPON DATA90. Atherosclerosis 215: 209-213, 2011.

5. Takashima N, Miura K, Hozawa A, et al. Population attributable fraction of smoking and metabolic syndrome on cardiovascular disease mortality in Japan: a 15 -year follow up of NIPPON DATA 90. BMC Public Health 10: 306, 2010.

Medical Check-up Center, Tachikawa Medical Center, Japan

Received for publication April 8, 2013; Accepted for publication April 16, 2013

Correspondence to Dr. Eiji Oda, ijie@ venus.sannet.ne.jp

(C) 2013 The Japanese Society of Internal Medicine Journal Website: http://www.naika.or.jp/imonline/index.html 